\title{
Character profiles and the activation of predictive inferences
}

\author{
KELLY A. PERACCHI and EDWARD J. O'BRIEN \\ University of New Hampshire, Durham, New Hampshire
}

\begin{abstract}
Most evidence indicates that with supportive context, predictive inferences do become activated. The present experiments were designed to investigate whether the characteristics of the protagonist can mitigate against activation of a predictive inference, even when the immediately preceding context supports it. Participants read passages containing a detailed description of characteristics of the protagonist. The characteristics were either consistent, inconsistent, or neutral with respect to a subsequent predictive inference. This character information was followed by a context that supported the predictive inference. Experiment 1 demonstrated that predictive inferences were activated, except when they conflicted with the characteristics of the protagonist. Experiment 2 demonstrated that when an inference was activated, it was also instantiated into the representation of the text. These results are discussed in terms of the memory-based view of text processing.
\end{abstract}

All theories of reading comprehension contain an assumption that readers engage in some inferential processing during reading (e.g., Graesser, Singer, \& Trabasso, 1994; McKoon \& Ratcliff, 1992; van Dijk \& Kintsch, 1983; Zwaan \& Radvansky, 1998). However, one of the central differences among many of these models is the extent to which readers actively engage in processes that lead to the activation of inferential information. Some theories focus more heavily on inferencing as an active part of the comprehension process (e.g., Graesser et al., 1994; Kintsch, 1998; Singer, Graesser, \& Trabasso, 1994; Zwaan \& Radvansky, 1998), whereas other theories focus much more on the passive activation of inferential information (e.g., Kintsch, 1988; McKoon \& Ratcliff, 1992; Myers \& O'Brien, 1998; O’Brien \& Myers, 1999).

Regardless of how they are activated, the types of inferences that become available during reading fall into two broad classifications: necessary and elaborative. Necessary inferences are those that are typically required for the reader to fully comprehend an intended message (e.g., bridging and causal inferences), whereas elaborative inferences are not necessary for comprehension but rather expand upon and flesh out what has been explicitly stated in the text (e.g., category instantiation and predictive inferences). Although good agreement exists that necessary inferences become activated and instantiated

This research was supported in part by National Science Foundation Grant SBR-9631040 awarded to E.J.O. Portions of this research were presented in 2002 at the 43rd annual meeting of the Psychonomic Society in Kansas City, MO. The complete set of materials is available on request from the first author. We thank Anne Cook, Sabine Gueraud, and Mary Harmon for helpful comments and suggestions. Correspondence should be addressed to K. A. Peracchi, Department of Psychology, University of New Hampshire, Durham, NH 03824 (e-mail: kelly.peracchi@unh.edu). into the representation, the extent to which elaborative inferences become activated and instantiated is less clear. The goal of the present article is to further explore both the conditions under which predictive inferences become activated and the extent to which readers make use of that information.

Both necessary and elaborative inferences can occur through either passive activation or active generation (Kintsch, 1993, 1998). Through passive activation, preexisting knowledge structures, such as relevant portions of general world knowledge, initially become available as a result of low-level priming (e.g., Albrecht \& O'Brien, 1993; Ericsson \& Kintsch, 1995; Garrod, O’Brien, Morris, \& Rayner, 1990; McKoon \& Ratcliff, 1992; Myers \& O'Brien, 1998; O’Brien, 1995; O'Brien \& Albrecht, 1991). This process occurs when concepts or lexical items currently active in memory prime related concepts and/or long-term memory knowledge structures (e.g., Ericsson \& Kintsch, 1995). In contrast, active inferencing involves the generation of new information that is derived on the basis of information in the text through some inference procedure. Active inferential processes are strategic. They involve a directed, strategic, resourcedemanding search of long-term memory in order to locate specific types of information (e.g., Graesser et al., 1994; Long, Seely, \& Oppy, 1996; Singer et al., 1994).

The memory-based text processing view (e.g., Gerrig \& McKoon, 1998; McKoon, Gerrig, \& Greene, 1996; McKoon \& Ratcliff, 1995), and in particular the resonance model (e.g., Myers \& O'Brien, 1998; O’Brien \& Myers, 1999), provides a reasonable account of passive inference activation. According to this view, each concept or proposition that is encoded sends a signal to all of memory - that is, both to the episodic memory trace of earlier portions of text and to general world knowledge. The process is one in which concepts and proposi- 
tions in the discourse representation and in the reader's knowledge base resonate as a function of the degree of match to the input. This match depends on both the featural overlap among concepts and the argument overlap of propositions. Memory elements that are contacted by the initial signal in turn signal to other memory elements. During this resonance process, activation builds, and when the process stabilizes, the most active elements enter working memory. It is important to note that the elements that will enter working memory are not determined solely by low-level priming of simple concepts or lexical items contained in the text; instead, activated elements are determined by an interaction of resonating elements presented in the text; information contained in both active and inactive portions of the situation model; and related information contained in general world knowledge.

There are two critical features of the resonance process. First, it is continual: A signal is being sent to all of memory constantly, not just when triggered by a coherence break. What is resonating in long-term memory changes constantly with each change in the contents of working memory. More importantly, the resonance process is dumb: Any information that resonates sufficiently is returned to active memory, independent of whether that information will ultimately facilitate or hinder comprehension (e.g., O'Brien, Rizzella, Albrecht, \& Halleran, 1998).

The resonance model can readily account for the activation of many types of necessary inferences, such as anaphoric inferences (e.g., McKoon \& Ratcliff, 1980; O'Brien, Duffy, \& Myers, 1986), bridging inferences (e.g., Clark \& Sengul, 1979; Haviland \& Clark, 1974; Keenan, Potts, Golding, \& Jennings, 1990; McKoon \& Ratcliff, 1990; Sanford, 1990), and causal inferences (e.g., Rizzella \& O’Brien, 1996; van den Broek, 1990a, 1990b, 1994). Although these types of inferences can be actively generated, it is generally assumed that they occur through the passive activation of preexisting knowledge structures. (See Myers \& O'Brien, 1998, and O'Brien \& Myers, 1999, for reviews of the research.)

The memory-based text processing view can also be used to explain many types of elaborative inferences. These include instantiating an explicit member of a category when presented with a category label (e.g., Garrod et al., 1990; O'Brien, Shank, Myers, \& Rayner, 1988), inferring an antecedent to an anaphor rather than completing a search of memory for the appropriate antecedent (e.g., O'Brien \& Albrecht, 1991), and the activation of predictive inferences when they have sufficient supporting context (Calvo \& Castillo, 1996; Calvo, Castillo, \& Estevez, 1999; Cook, Limber, \& O’Brien, 2001; FincherKiefer, 1995, 1996; Keefe \& McDaniel, 1993; Klin, Guzman, \& Levine, 1999; Klin, Murray, Levine, \& Guzman, 1999; Murray, Klin, \& Myers, 1993).

Consider the resonance model as it applies to predictive inferences. As with other elaborative inferences, the strength of the supporting context is essential for the ac- tivation of predictive inferences. For example, Murray et al. (1993) presented passages that contained several text characteristics that would increase the probability that a predictive inference would become activated. Consider the following passage:

Carol was fed up with her job waiting on tables. Customers were rude, the chef was impossibly demanding, and the manager had made a pass at her just that day. The last straw came when a rude man at one of her tables complained that the spaghetti she had just served was cold. As he became louder and nastier, she felt herself losing control. Without thinking of the consequences, she picked up the plate of spaghetti, and raised it above the rude man's head.

They found that participants were faster to name the inferred concept ("dump") aloud in the predictive condition than in a control condition in which the last sentence was changed to Without thinking of the consequences, she picked up the plate of spaghetti, and walked away. Consistent with the resonance model, when there is sufficient context supporting a particular predictive inference, concepts representing that inference will receive increased levels of activation, resulting in faster naming times relative to a control condition.

Implicit in much of the work on predictive inferences are the ideas that the supportive context must (1) always contain strong semantic associates of the inference; (2) immediately precede the point at which activation of the predictive inference is measured; or (3) maintain the predictive inference in active memory (e.g., Keefe \& McDaniel, 1993; McDaniel, Schmalhofer, \& Keefe, 2001; Murray et al., 1993; Schmalhofer, McDaniel, \& Keefe, 2002). Cook et al. (2001) tested these assumptions by eliminating the strong semantic associates and presenting the constraining context well before the point at which activation of the inference was measured. Despite these changes, the researchers continued to find activation of predictive inferences. Cook et al. argued that even when the immediately preceding context was neutral with respect to a predictive inference, information contained in the situation model could result in activation of the inference. In a result consistent with this finding, Schmalhofer et al. (2002) have both demonstrated and simulated activation of predictive inferences solely at the level of the situation model.

Both Cook et al. (2001) and Keefe and McDaniel (1993) have shown that a constraining context is necessary for the activation of a predictive inference. In combination, these results indicate that predictive inferences can be activated when the constraining information is either in the immediately preceding context or contained in the situation model. Although these findings can be interpreted within the memory-based text processing view of inference activation (e.g., Gerrig \& McKoon, 1998; Myers \& O'Brien, 1998; O'Brien \& Myers, 1999), they are also consistent with the constructionist view of inferential processing (e.g., Graesser et al., 1994; Singer et al., 1994). The primary purpose of this study was not to discriminate between these two competing theories but instead to ex- 
tend knowledge of the conditions and factors that influence the activation of predictive inferences.

The present set of experiments was designed to further assess the impact that both the immediately preceding context and the information contained in the situation model have on the activation of predictive inferences. Specifically, does a predictive inference still become active when it is consistent with the immediately preceding context but not with other information present in the situation model?

For example, consider the passage from Murray et al. (1993) presented earlier. When readers were presented with passages that described the frustrated waitress raising a plate of spaghetti above a rude customer's head, the concept "dump" became activated. However, other research has shown that what the reader knows about the characteristics of the protagonist (i.e., the character profile) influences how they interpret subsequent events (Albrecht \& O'Brien, 1993; O’Brien et al., 1998; Rapp, Gerrig, \& Prentice, 2001) and that such information is maintained in the active portion of the situation model (e.g., Zwaan \& Radvansky, 1998). What would happen if the waitress had previously been described as meek and mild, as someone who would never harm anyone? Would the concept "dump" still become activated? Prior work has shown that the immediately preceding context does lead to inference activation, but would activation still occur if the immediately preceding context were combined with information in the situation model that was inconsistent with the predictive inference? Experiment 1 was designed to answer this question by determining whether predictive inferences are activated when the immediately preceding context supports the inference but information in the situation model does not. Experiment 2 was designed to assess whether activated predictive inferences are instantiated into the long-term memory representation of the text.

\section{EXPERIMENT 1}

In Experiment 1, the participants read 20 narrative passages, each one appearing in four conditions. An example is presented in Table 1. Each passage presented a situation (e.g., Carol dealing with a rude customer) that supported the activation of a to-be-inferred concept (e.g., "dump"). This context was followed by either an inference-evoking or a neutral sentence. This contextual information was preceded by one of three character trait conditions: In the consistent condition, the protagonist's profile was consistent with the to-be-inferred concept (e.g., Carol had a short temper); in the inconsistent condition, the protagonist's profile was inconsistent with or opposed to the to-be-inferred concept (e.g., Carol was known for her ability to peacefully settle any confrontation); the neutral condition described a character trait that was unrelated to the predicted concept (e.g., Carol loved her kids). The consistent, inconsistent, and neutral conditions were always followed by an inference-evoking sentence (e.g., Carol lifted the spaghetti above his head.). A baseline condition was also included in which the neutral elaboration was followed by a neutral, or noninference-evoking, sentence (e.g., She lifted the spaghetti and walked away.). Following each version of the passage, the participants were asked to name a predictive inference out loud (e.g., "dump"). ${ }^{1}$ Naming times in the consistent and neutral conditions should be shortest, because the inference should have been activated. Naming times in the baseline condition should be longest, because the inference would not have been activated by the target sentence. The interesting question is what will happen in the inconsistent condition? If a character profile is able to mitigate against activation of a predictive inference, then the inconsistent condition (e.g., Carol is described as peaceful) should produce naming times that are close to those in the baseline condition. If the character profile is not able to mitigate against activation, then the naming times in the inconsistent condition should be closer to those in the consistent and neutral conditions, so that the naming times in all three of these conditions will be faster than those in the baseline condition.

Table 1

Example Passage Used in Experiment 1

\section{Introduction}

Carol was a single mother with two young children. She had to work two jobs to make ends meet. She worked full-time as a teacher and part-time as a waitress. She hated not having much free time.

Consistent Trait Elaborated

Carol was known for her short temper and her tendency to act without thinking. She never thought about the consequences of her actions, so she often suffered negative repercussions. She refused to let people walk all over her. In fact, she had just gotten a ticket for road rage. She decided she would never put up with anyone that was not nice to her. One particular night, Carol had an extremely rude customer. He complained about his spaghetti, and he yelled at Carol as if it was her fault.

Inconsistent Trait Elaborated

Carol was known for her ability to peacefully settle any confrontation. She would never even think to solve her problems with physical violence. She taught her students and her own children how to solve problems through conversation. She believed this was an effective way to stop the increasing violence in the schools. Carol also helped other parents learn to deal with their anger. One particular night, Carol had an extremely rude customer. He complained about his spaghetti, and he yelled at Carol as if it was her fault.

\section{Neutral Trait Elaborated}

Carol loved her kids and would do whatever it took to keep them. She was thankful that she was granted sole custody after the divorce. She didn't know what she would have done if she lost her children. She tried to make the time that they had together meaningful. They ate dinner together every night and she always planned a fun event for the weekend. One particular night, Carol had an extremely rude customer. He complained about his spaghetti, and he yelled at Carol as if it was her fault.

Inference-Evoking Sentence

Carol lifted the spaghetti above his head.

Baseline Condition

She lifted the spaghetti and walked away.

Probe

dump 


\section{Method}

Participants. The participants were 40 University of New Hampshire undergraduates who received course credit for their involvement in the experiment.

Materials. The materials were 20 narrative passages. An example is presented in Table 1. Each passage was divided into four sections: introduction, elaboration - which included the supportive context as the last couple of sentences - and an inference-evoking or noninference-evoking sentence. Each passage began with an introductory section that introduced the protagonist of the story. This section was followed by one of three elaboration sections that described a specific character trait of the protagonist: consistent, inconsistent, or neutral. The mean lengths (and standard deviations) of the elaboration sections for the consistent, inconsistent, and neutral conditions were 63.50 (1.76), 63.20 (1.82), and 63.40 (1.70) words, respectively. The consistent elaboration described the protagonist as having character traits that were consistent with the inference. The inconsistent elaboration described in the protagonist character traits that were inconsistent with the inference. Finally, the neutral elaboration described character traits in the protagonist that were unrelated to the inference.

After the elaboration, a section of approximately 21 words was presented that supported the activation of the predicted concept. In all conditions except the baseline, the inference-evoking sentence (mean character length, 40.65; standard deviation, 2.16) immediately followed the supportive context. In the baseline condition, the neutral context was presented and was followed by a neutral sentence (mean character length, 39.95; standard deviation, 1.57).

Because inference-evoking sentences were used in three out of the four conditions, 10 filler passages that did not activate an inference were included. In this way, each participant read 15 passages that were designed to elicit a predictive inference and 15 that were not. No data were recorded for the filler passages.

Each passage was followed by a comprehension question in order to ensure that the participants were reading the passages carefully. Questions focused on information from each passage that did not relate to the character profiles. Equal numbers of "yes" and "no" comprehension questions were asked.

Four material sets were constructed. Each set contained 30 passages: 5 in each of the four conditions, plus an additional 10 filler passages. Across the four material sets, each experimental passage appeared only once in each of the conditions.

Procedure. The participants were randomly assigned to one of four material sets. Each participant was run individually in a session that lasted approximately $1 \mathrm{~h}$. All materials were presented on a video monitor controlled by a Dell 386 microcomputer.

The participants were instructed to rest their right thumbs on the line-advance key, their right index fingers on a "yes" key, and their left index fingers on a "no" key. Each trial began with the word READY appearing in the middle of the screen. When the participants were ready to read a passage, they pressed the line-advance key. Texts were presented one line at a time. Each line was a line of naturally occurring text no longer than 46 characters. Each press of the line-advance key erased the current line and presented the next line. Each participant was instructed to read at a comfortable, normal reading pace. Following the last line of each passage, the cue XXXX appeared for $500 \mathrm{msec}$ and was replaced by a probe word. The participants were instructed to name the probe word aloud as quickly as possible. When the word was named, a voice key triggered, the probe word was erased from the screen, and the naming time for the word was recorded. After the probe word disappeared, the cue QUESTIONS appeared in the middle of the screen for 2,000 msec. This cue was followed by a comprehension question to which the participants responded by pressing either the "yes" or the "no" key. There were equal numbers of "yes" and "no" comprehension questions. On the trials in which the participants made errors, the word ERROR appeared in the middle of the screen for $750 \mathrm{msec}$. Before beginning the experimental passages, the participants read three practice pas-
Table 2

\begin{tabular}{lcccc}
$\begin{array}{c}\text { Mean Naming and Reading Times (in msec) as Functions of } \\
\text { Character Trait Condition in Experiment 1 }\end{array}$ \\
\hline & Consistent & Inconsistent & Neutral & Baseline \\
\hline Naming time & 506 & 527 & 514 & 525 \\
Reading time & 1,761 & 1,770 & 1,797 & 1,864 \\
\hline
\end{tabular}

sages in order to ensure that they were thoroughly familiarized with and understood the procedure.

\section{Results}

For naming time analyses, all scores that were 2.5 standard deviations beyond the mean for a participant were eliminated, along with all voice key failures. This filtering resulted in the exclusion of approximately $8.9 \%$ of the naming time data. For reading time analyses, all scores that were 2.5 standard deviations beyond the mean for a participant were eliminated. Across all experiments reported, this process resulted in the exclusion of approximately $2.5 \%$ of the reading time data. In all analyses reported, $F_{1}$ always refers to tests against error terms based on participant variability and $F_{2}$ always refers to tests against an error term based on item variability. All analyses were significant at the standard alpha level of .05 unless otherwise indicated.

The mean naming times for the predictive inference in Experiment 1 appear in Table 2. There was a significant effect of character trait condition $\left[F_{1}(3,108)=7.11\right.$, $\left.M S_{\mathrm{e}}=528.60 ; F_{2}(3,48)=7.66, M S_{\mathrm{e}}=552.60\right]$. Planned comparisons revealed that naming times for the predictive inference were faster in the consistent condition than in either the inconsistent condition $\left[F_{1}(1,36)=16.98\right.$, $\left.M S_{\mathrm{e}}=967.28 ; F_{2}(1,16)=13.03, M S_{\mathrm{e}}=1,304.22\right]$ or the baseline condition $\left[F_{1}(1,36)=20.82, M S_{\mathrm{e}}=686.64\right.$; $\left.F_{2}(1,16)=16.10, M S_{\mathrm{e}}=1,051.70\right]$. Naming times for the predictive inference were also faster in the neutral condition than in either the inconsistent condition $\left[F_{1}(1,36)=\right.$ $\left.6.10, M S_{\mathrm{e}}=1,109.09 ; F_{2}(1,16)=5.42, M S_{\mathrm{e}}=1,382.85\right]$ or the baseline condition $\left[F_{1}(1,36)=7.17, M S_{\mathrm{e}}=\right.$ $\left.757.67 ; F_{2}(1,16)=4.90, M S_{\mathrm{e}}=1,519.42\right]$.

Reading times were also taken for the inference-evoking sentence in order to determine whether that sentence produced any differences in comprehension difficulty as a function of inference generation. The mean reading times are also presented in Table 2. The overall effect of character trait condition was not significant $\left[F_{1}(3,108)=\right.$ $2.19, M S_{\mathrm{e}}=39,365.23 ; F_{2}(3,48)=2.23, M S_{\mathrm{e}}=$ $31,521.61]$. Reading times for the target sentence in the consistent, inconsistent, and neutral conditions did not reliably differ from one another $(p>.05)$. However, planned comparisons revealed that reading times for the neutral sentence used in the baseline condition were significantly slower than reading times for the inferenceevoking sentence in the consistent condition $\left[F_{1}(1,36)=\right.$ 4.15, $\left.M S_{\mathrm{e}}=101,986.00\right]$ and in the inconsistent condition $\left[F_{1}(1,36)=5.39, M S_{\mathrm{e}}=64,553.01\right]$. The analyses based on item variability failed to reach significance for 
these two contrasts $\left[F_{2}(1,16)=2.82, M S_{\mathrm{e}}=71,312.14\right.$; $F_{2}(1,16)=3.78, M S_{\mathrm{e}}=98,619.52$, respectively]. Thus, there was no systematic relationship between reading and naming times.

\section{Discussion}

The naming time results indicated that the character trait information contained in the situation model was able to mitigate against activation of a predictive inference. Naming times in the inconsistent and baseline conditions did not differ reliably, indicating that the inference was not activated in the inconsistent condition. As was the case in prior work (e.g., Cook et al., 2001; Keefe \& McDaniel, 1993; Murray et al., 1993), naming times in the consistent and neutral conditions were faster than those in the baseline condition, indicating that the predictive inference had been activated. Thus, the overall pattern of naming times indicated that predictive inferences were activated by a supportive context that immediately preceded the point at which activation was measured, as long as information in the situation model did not contradict that inference. However, if the supportive context was preceded by character trait information that contradicted the predictive inference, the inference was not activated. Further discussion will be postponed until after we present the results of Experiment 2.

\section{EXPERIMENT 2}

Experiment 1 demonstrated that the profile of the protagonist influences whether or not a predictive inference becomes activated. However, it did not address whether the inference merely represents fleeting activation of a concept or whether the inference becomes encoded as part of the reader's representation of the text. Earlier studies have suggested that unless the text supports the inference, it is not encoded as part of the representation (Fincher-Kiefer, 1996; Keefe \& McDaniel, 1993). A recent study (Klin, Guzman, \& Levine, 1999) found that predictive inferences may be encoded more than has previously been thought, however, because earlier studies had used probe tasks, which are sensitive only to immediate activation. In addition, Cook et al. (2001) showed that predictive inferences may be encoded, but that what is encoded is likely to be a more general concept rather than a specific lexical item. They suggested that over time, activation of the specific lexical item decays and the reader is left with only a general concept of what happened. Thus, an inference may be activated but not encoded as part of the representation; on the other hand, a general concept may be both activated and encoded but not detected by a naming time task. Therefore, lack of a finding of immediate activation in a naming task does not preclude the possibility that an inference has been activated, and possibly encoded. Experiment 2 was designed (1) to determine whether or not, in the consistent condition, readers encoded a general concept representing the predictive inference,
Table 3

Sample Passage Used in Experiment 2

\section{Introduction}

Carol was a single mother with two young children. She had to work two jobs to make ends meet. She worked full-time as a teacher and part-time as a waitress. She hated not having much free time.

\section{Consistent Trait Elaborated}

Carol was known for her short temper and her tendency to act without thinking. She never thought about the consequences of her actions, so she often suffered negative repercussions. She refused to let people walk all over her. In fact, she had just gotten a ticket for road rage. She decided she would never put up with anyone that was not nice to her. One particular night, Carol had an extremely rude customer. He complained about his spaghetti, and he yelled at Carol as if it was her fault.

Inconsistent Trait Elaborated

Carol was known for her ability to peacefully settle any confrontation. She would never even think to solve her problems with physical violence. She taught her students and her own children how to solve problems through conversation. She believed this was an effective way to stop the increasing violence in the schools. Carol also helped other parents learn to deal with their anger. One particular night, Carol had an extremely rude customer. He complained about his spaghetti, and he yelled at Carol as if it was her fault.

Inference-Evoking Sentence

Carol lifted the spaghetti above his head.

Filler

She realized how tired she was. She had gotten up at 5:00 that morning and went for a run. She taught school all day and only had time to run home and change in between jobs. She couldn't wait to go to bed. She looked down at her customer.

Consistent Critical Sentence

The man wiped spaghetti off of his head.

Consistent Spillover Sentence

Carol dropped the plate and walked out.

Inconsistent Critical Sentence

He thanked her for the fresh spaghetti.

Inconsistent Spillover Sentence

$\mathrm{He}$ even asked Carol for a dessert menu.

Closing

That night Carol was too tired to play with her kids. She promised to take them to the park the next day.

and (2) to provide converging evidence that the predictive inference was not activated in the inconsistent condition.

The participants read the same passages as in Experiment 1 , with a few modifications (see Table 3 ). First, only the consistent and inconsistent character profiles were used. Second, only the inference-evoking target sentence was used (e.g., Carol lifted the spaghetti above his head.). Following this sentence, three or four filler sentences were presented in order to shift the focus of the passage away from the inference to a neutral topic. Keefe and McDaniel (1993) have shown that activation of a predictive inference decays after one filler sentence unless it has been encoded as part of the reader's representation. Thus, three to four filler sentences are sufficient to ensure that unless the inference has been encoded, any fleeting activation will have decayed. This filler section was followed by one of two types of critical sentence pairs: consistent (e.g., The man wiped spaghetti off of his 
head. Carol dropped the plate and walked out.) or inconsistent (e.g., He thanked her for the fresh spaghetti. He even asked Carol for a dessert menu.). That is, the critical sentence pairs were either consistent or inconsistent with the predictive inference. The second sentence in each pair was a spillover sentence designed to detect any delayed or continued slowdown in reading times.

Consider the consistent character profile passages: When paired with the consistent critical sentences, readers should not experience any comprehension difficulty if the inference, (e.g., "dump") has previously been activated and encoded. In contrast, when the consistent character profile is followed by the inconsistent sentences, readers should experience comprehension difficulty (e.g., he is thanking her for the fresh plate of spaghetti after she dumped it on his head). ${ }^{2}$ Next, consider the inconsistent character profile passages - here the opposite pattern would be expected: When the inconsistent profile is followed by the consistent critical sentences, a slowdown in reading times should occur, because the critical sentence is consistent with an inference that has neither been activated nor encoded (e.g., he is wiping spaghetti off his head even though she never dumped it). In contrast, when this character profile is paired with the inconsistent critical sentences, there is no contradiction, because the inference was never activated (e.g., he thanks her for the fresh plate of spaghetti after she did NOT dump it on his head). Therefore, no slowdown should occur.

\section{Method}

Participants. The participants were 40 University of New Hampshire undergraduates who were enrolled in introductory psychology courses and had not participated in Experiment 1. The participants received partial course credit for their involvement in the experiment.

Materials. The materials were the same 20 passages used in Experiment 1, with a few modifications: Only the consistent and inconsistent character profiles and only the inference-evoking target sentence were used. Following the target sentence, a filler paragraph was presented that shifted the focus of the passage away from the inference to a neutral topic. The filler section had a mean of 48.45 words and a standard deviation of 2.46 words. This filler section was followed by one of two combinations of critical and spillover sentences. The critical sentence was either consistent or inconsistent with the inference. The consistent critical sentence and corresponding spillover sentence each had a mean length of 39.8 characters and standard deviations of 1.36 and 1.43 characters, respectively. The inconsistent critical and corresponding spillover sentences had mean lengths of 39.75 and 39.15 and standard deviations of 1.61 and 1.39 characters, respectively. The passages ended with a brief closing section, which was composed of two to three sentences. As in Experiment 1, each passage was followed by a comprehension question in order to ensure that the participants were reading the passages carefully. Questions focused on information from the passage that did not relate to the character profiles. There were equal numbers of "yes" and "no" comprehension questions.

Test passages were arranged into four material sets. Each set contained five passages that appeared in each of the four conditions. Across the four material sets, each passage appeared only once in each of the four conditions.

Procedure. The procedure for Experiment 2 was the same as for Experiment 1, except that no probe word was presented.

\section{Results and Discussion}

The mean reading times for Experiment 2 appear in Table 4. The critical and spillover sentences were analyzed separately. For the first critical sentence, the effect of character profile was not significant $\left[F_{1}(1,36)=.00, M S_{\mathrm{e}}=\right.$ $\left.84,770.57 ; F_{2}(1,16)=.02, M S_{\mathrm{e}}=37,256.42\right]$, nor was the consistency of the critical sentence $\left[F_{1}(1,36)<.00\right.$, $\left.M S_{\mathrm{e}}=61,382.15 ; F_{2}(1,16)=.05, M S_{\mathrm{e}}=217,246.34\right]$. However, the interaction between the type of character profile and the type of critical sentence was reliable $\left[F_{1}(1\right.$, $36)=48.96, M S_{\mathrm{e}}=56,576.38 ; F_{2}(1,16)=22.49, M S_{\mathrm{e}}=$ 44,167.74]. Planned comparisons revealed that for the consistent profile passages, reading times were longer for the inconsistent than for the consistent critical sentences $\left[F_{1}(1,36)=31.29, M S_{\mathrm{e}}=88,603.65 ; F_{2}(1,16)=4.57\right.$, $\left.M S_{\mathrm{e}}=174,839.59\right]$. In contrast, for the inconsistent profile passages, reading times were significantly longer for the consistent than for the inconsistent critical sentences $\left[F_{1}(1,36)=18.79, M S_{\mathrm{e}}=147,313.42\right]$. However, this difference was only marginally significant when tested against item variability $(p<.10)\left[F_{2}(1,16)=3.47\right.$, $\left.M S_{\mathrm{e}}=347,988.57\right]$. There were no differences in reading time for any of the spillover sentences.

The reading times from Experiment 2 provided converging evidence for the finding from Experiment 1 that readers instantiated the predictive inference when that inference was consistent with the profile of the protagonist, but did not instantiate the inference when it was inconsistent with the protagonist's profile. For example, when the protagonist Carol was described as frustrated (consistent character profile), lifting the plate of spaghetti should have led to the activation and instantiation of the inference "dump." Consistent with this view, reading times on the critical sentence were slower when that sentence was inconsistent with the predictive inference (e.g., $\mathrm{He}$

Table 4

Mean Reading Times (in Milliseconds) as a Function of Character Profile and Critical Sentence Type in Experiment 2

\begin{tabular}{|c|c|c|c|c|}
\hline & \multicolumn{4}{|c|}{ Character Profile } \\
\hline & \multicolumn{2}{|c|}{ Consistent Character Profile } & \multicolumn{2}{|c|}{ Inconsistent Character Profile } \\
\hline & $\begin{array}{l}\text { Consistent } \\
\text { CST }\end{array}$ & $\begin{array}{c}\text { Inconsistent } \\
\text { CST }\end{array}$ & $\begin{array}{l}\text { Consistent } \\
\text { CST }\end{array}$ & $\begin{array}{l}\text { Inconsistent } \\
\text { CST }\end{array}$ \\
\hline Critical sentence & 1,849 & 2,112 & 2,111 & 1,848 \\
\hline Spillover sentence & 1,835 & 1,858 & 1,867 & 1,776 \\
\hline
\end{tabular}

Note-CST, critical sentence type. 
thanked her for the fresh spaghetti.) than when the critical sentence was consistent with it (e.g., The man wiped spaghetti off of his head.). In contrast, when Carol was described as meek and mild (inconsistent character profile), lifting the plate of spaghetti should not produce activation and instantiation of the predictive inference "dump," leading to the opposite pattern of reading times. This pattern also occurred: Reading times were longer when the critical sentence was consistent with the predictive inference (e.g., The man wiped spaghetti off of his head.) than when the critical sentence was inconsistent with it (e.g., He thanked her for the fresh spaghetti.).

\section{GENERAL DISCUSSION}

The experiments in this paper addressed whether the character profile of the protagonist can mitigate against the activation of a predictive inference. Previous research has shown that predictive inferences become activated during reading either when the supportive context immediately precedes the point at which activation is measured (e.g., Klin, Guzman, \& Levine, 1999; Klin, Murray, et al., 1999) or when the supporting context appeared earlier but is in an active portion of the situation model (Cook et al., 2001). Also, this previous work has shown that once activated, some change in the representation takes place as a function of this initial activation. Klin, Guzman, and Levine (1999) argued that the specific lexical item is encoded, whereas Cook et al. (2001) argued that something more general that represents the idea of the inference is what gets encoded. But what would happen if the profile of the protagonist (i.e., a supportive context presented earlier in the text that is still part of the active portion of the situation model) conflicted with the immediately preceding context? Would the predictive inference still be activated, and would anything be instantiated as part of the representation of the text?

In Experiment 1, the character profile was either consistent, inconsistent, or neutral with respect to the predictive inference prompted by the last sentence of the passage. If information concerning the protagonist's profile contained in the situation model did not influence inference activation, then the predictive inference should have been activated in all conditions - that is, reading Carol lifted the plate of spaghetti above his head should have activated the inference "dump" in all conditions. However, when the protagonist was described as someone who was meek and mild and would never harm anyone, naming times for the inference "dump" did not differ reliably from the baseline condition, suggesting that despite the strong immediate context, the inference was not activated. In all other conditions, the inference was activated by the immediately preceding context.

These results can be interpreted within the resonance model. Whether or not the character trait information could mitigate against the activation of a predictive inference would depend on what information became activated. According to the resonance model, any informa- tion that shares semantic or contextual features with the information in working memory will be returned (e.g., Myers \& O'Brien, 1998; O'Brien \& Myers, 1999). When a reader is presented with an inference-evoking sentence about a character's actions (e.g., Carol lifted the plate of spaghetti above his head.), previous information regarding that character, including character traits, will be returned. Therefore, Carol lifting the spaghetti above the customer's head will activate information about whether Carol was peaceful, violent, or loved her kids. When Carol was described as peaceful, this information would mitigate against the activation from the immediately preceding context. Activation would thus be split between information that Carol would never engage in a violent act and activation on "dump" received from the inferenceevoking sentence. This conflict would reduce the activation converging on the concept "dump," decreasing the likelihood that the concept would enter working memory. This result, however, does not necessarily mean that the inference would receive no activation in the inconsistent condition. Some activation might have converged on the inference, but not enough for the activation to be detected.

That activation may split among competing concepts, and that this splitting can reduce the activation of a predictive inference, was first demonstrated by Klin, Guzman, and Levine (1999). They found activation of a predictive inference (e.g., "break" after reading that a delicate vase had been thrown against a wall) in the inference version relative to the control version of a passage. However, then they added an additional consequence to the introduction of the passage, as in the example below.

\footnotetext{
After years of abuse, Susan had enough. She joined a support group for battered women and told her husband, Steven, that she was going to leave him if there was even the mildest violence incident in the house. Steven was taking her seriously and had started counseling. He had managed to control his temper for the past month. He couldn't bear the thought of her leaving. He felt his life would be over if she and the children left. Today Steven was angry at Susan because she had left a mess in the kitchen. He tried to cool down, but felt his resentment building. No longer able to control his anger, he threw a delicate porcelain vase against the wall.
}

In this new context, Klin et al. no longer found activation of the inference, even though the probability of the inference occurring (e.g., the vase breaking) did not change. They argued that the signal from the inferenceevoking sentence (e.g., He threw a delicate porcelain vase against the wall.) was now divided between the inference concept ("break") and the additional consequence section of the story. Because only the $n$ most active elements receive sufficient activation to enter working memory, the concept "break" was excluded because it was no longer one of the $n$ most active elements.

A second possibility is that there may have been momentary activation of "dump" (or of "break" in the pas- 
sage above) sufficient to enter working memory, but that during an integration stage, as in Kintsch's (1998) C-I model, the contextual information available in the discourse model led to a pattern of activation stabilization that quickly reduced or eliminated the activation. A direct test of this possibility would require testing sooner than $500 \mathrm{msec}$ after reading the inference-evoking sentence. With either possibility, however, it is clear that contextual information in the discourse model influenced the activation of a predictive inference.

Experiment 2 was designed to assess whether the predictive inference was instantiated into the representation of the text. As indicated earlier, immediate activation of a concept does not assure that it will be encoded as part of the representation, and because inferences often involve the activation of a general concept rather than a specific lexical item (e.g., Cook et al., 2001), the lack of activation of a specific lexical item (as in the inconsistent condition in Experiment 1) does not ensure that no inferential processing of a general concept has resulted in a change in the memory representation. The results of our experiment confirmed that the predictive inference was instantiated in the consistent but not in the inconsistent condition. For the consistent character profile passages, participants exhibited a slowdown in reading when the critical sentence contradicted the inference, indicating that the inference had been instantiated. In contrast, for the inconsistent profile passages, an opposite pattern occurred-reading times were slower when the critical sentences were consistent with the inference, indicating that the inference had not instantiated.

These results are consistent with the conclusions of Cook et al. (2001) that inference-evoking sentences activate not only the contextual support in the immediately preceding sentence but all relevant information in the situation model. In terms of the passage in Table 1, not only does the information about the rude angry customer become activated, but also the information about the waitress's character traits. In this case, the information contained in the model actually governs what is likely to be activated and instantiated.

The experiments presented in this paper also extend Rapp et al.'s (2001) work, which indicated that readers encode and apply trait-based character models during reading. Rapp et al. claimed that readers use trait-based information to generate expectations about what will happen in the text; however, the researchers did not say when these expectations would occur during reading. The present experiments suggest that readers apply character trait information to make predictions about a character's actions before these actions are stated in the text.

The present research adds to a growing set of results that indicate that the factors governing the activation and instantiation of a predictive inference are not restricted to the immediately preceding context. Instead, predictive inferences are governed by what is "readily available" to the reader, including not only the immediately preceding context, but also information contained in the situation model.

\section{REFERENCES}

Albrecht, J. E., \& O’Brien, E. J. (1993). Updating a mental model: Maintaining both local and global coherence. Journal of Experimental Psychology: Learning, Memory, \& Cognition, 19, 1061-1070.

Calvo, M. G., \& Castillo, M. D. (1996). Predictive inferences occur on-line, but with delay: Convergence of naming and reading times. Discourse Processes, 22, 57-78.

Calvo, M. G., Castillo, M. D., \& Estevez, A. (1999). On-line predictive inferences in reading: Processing time during versus after the priming context. Memory \& Cognition, 27, 834- 843.

Clark, H. H., \& SeNGUL, C. J. (1979). In search of referents for nouns and pronouns. Memory \& Cognition, 7, 35-41.

Cook, A. E., Limber, J. E., \& O'Brien, E. J. (2001). Situation-based context and the availability of predictive inferences. Journal of Memory \& Language, 44, 220-234.

ERICSSON, K. A., \& KINTSCH, W. (1995). Long-term working memory. Psychological Review, 102, 211-245.

FINCHER-KIEFER, R. (1995). Relative inhibition following the encoding of bridging and predictive inferences. Journal of Experimental Psychology: Learning, Memory, \& Cognition, 21, 981-995.

FINCHER-KIEFER, R. (1996). Encoding differences between bridging and predictive inferences. Discourse Processes, 22, 225-246.

ForSTER, K. (1981). Priming and the effects of sentence and lexical contexts on naming time: Evidence for autonomous lexical processing. Quarterly Journal of Experimental Psychology, 33A, 465-495.

Garrod, S., O'Brien, E. J., Morris, R. K., \& RAYNer, K. (1990). Elaborative inferencing as an active or passive process. Journal of Experimental Psychology: Learning, Memory, \& Cognition, 16, 250-257.

GERRIG, R. J., \& McKoon, G. (1998). The readiness is all: The functionality of memory-based text processing. Discourse Processes, 26, 67-86.

Graesser, A. C., Singer, M., \& Trabasso, T. (1994). Constructing inferences during narrative text comprehension. Psychological Review, 101, 371-395.

HAVILAND, S. E., \& Clark, H. H. (1974). What's new? Acquiring new information as a process in comprehension. Journal of Verbal Learning \& Verbal Behavior, 13, 512-521.

KeEFE, D. E., \& McDANiEL, M. A. (1993). The time course and durability of predictive inferences. Journal of Memory \& Language, $\mathbf{3 2}$, 446-463.

Keenan, J. M., Golding, J. M., Potts, G. R., Jennings, T. M., \& Aman, C. J. (1990). Methodological issues in evaluating the occurrence of inferences. In A. C. Graesser \& G. H. Bower (Eds.), Inferences and text comprehension (Vol. 25, pp. 295-312). San Diego: Academic Press.

Keenan, J. M., Potts, G. R., Golding, J. M., \& Jennings, T. M. (1990). Which elaborative inferences are drawn during reading? A question of methodologies. In D. A. Balota, G. B. Flores d'Arcais, \& $\mathrm{K}$. Rayner (Eds.), Comprehension processes in reading (pp. 377402). Hillsdale, NJ: Erlbaum.

KInTSCH, W. (1988). The role of knowledge in discourse comprehension: A construction-integration model. Psychological Review, $\mathbf{9 5}$, 163-182.

KINTSCH, W. (1993). Information accretion and reduction in text processing: Inferences. Discourse Processes, 16, 193-202.

KINTSCH, W. (1998). Comprehension: A paradigm for cognition. Hillsdale, NJ: Erlbaum.

Kuin, C. M., Guzman, A. E., \& Levine, W. H. (1999). Prevalence and persistence of predictive inferences. Journal of Memory \& Language, 40, 593-604.

KLIN, C. M., Murray, J. D., Levine, W. H., \& Guzman, A. E. (1999). Forward inferences: From activation to long-term memory. Discourse Processes, 27, 241-260.

LONG, D. L., SEELY, M. R., \& OPPy, B. L. (1996). The availability of causal information during reading. Discourse Processes, 22, 145170.

McDaniel, M. A., Schmalhofer, F., \& Keefe, D. E. (2001). What is minimal about predictive inferences? Psychonomic Bulletin \& Review, 8, 840-846.

McKoon, G., Gerrig, R. J., \& Greene, S. B. (1996). Pronoun resolution without pronouns: Some consequences of memory-based text 
processing. Journal of Experimental Psychology: Learning, Memory, \& Cognition, 22, 919-932.

McKoon, G., \& RATCLIFF, R. (1980). The comprehension processes and memory structures involved in anaphoric reference. Journal of Verbal Learning \& Verbal Behavior, 19, 668-682.

McKoon, G., \& Ratcliff, R. (1990). Textual inferences: Models and measures. In D. A. Balota, G. B. Flores d'Arcais, \& K. Rayner (Eds.), Comprehension processes in reading (pp. 403-421). Hillsdale, NJ: Erlbaum.

McKoon, G., \& Ratcliff, R. (1992). Inference during reading. Psychological Review, 99, 440-466.

McKoon, G., \& RatCLIFF, R. (1995). The minimalist hypothesis: Directions for research. In C. A. Weaver, S. Mannes, \& C. R. Fletcher (Eds.), Discourse comprehension: Essays in honor of Walter Kintsch (pp. 97-116). Hillsdale, NJ: Erlbaum.

Murray, J. D., Klin, C. M., \& Myers, J. L. (1993). Forward inferences in narrative text. Journal of Memory \& Language, 32, 464-473.

Myers, J. L., \& O'Brien, E. J. (1998). Accessing the discourse representation during reading. Discourse Processes, 26, 131-157.

O'Brien, E. J. (1995). Automatic components of discourse comprehension. In R. F. Lorch \& E. J. O'Brien (Eds.), Sources of coherence in reading (pp. 159-176). Hillsdale, $\mathrm{NJ}$ : Erlbaum.

O'Brien, E. J., \& Albrecht, J. E. (1991). The role of context in accessing antecedents in text. Journal of Experimental Psychology: Learning, Memory, \& Cognition, 17, 94-102.

O'Brien, E. J., \& Albrecht, J. E. (1992). Comprehension strategies in the development of a mental model. Journal of Experimental Psychology: Learning, Memory, \& Cognition, 18, 777-784.

O'Brien, E. J., CoOK, A. E., \& Peracchi, K. A. (2004). Updating situation models: Reply to Zwaan and Madden (2004). Journal of Experimental Psychology: Learning, Memory, \& Cognition, 30, 289-291.

O'Brien, E. J., Duffy, S. A., \& Myers, J. L. (1986). Anaphoric inference during reading. Journal of Experimental Psychology: Learning, Memory, \& Cognition, 12, 346-352.

O'BRIEN, E. J., \& MYERS, J. L. (1999). Text comprehension: A view from the bottom up. In S. R. Goldman, A. C. Graesser, \& P. van den Broek (Eds.), Narrative comprehension, causality, and coherence: Essays in honor of Tom Trabasso (pp. 36-53). Mahwah, NJ: Erlbaum.

O’Brien, E. J., Rizzella, M. L., Albrecht, J. E., \& Halleran, J. E. (1998). Updating a situation model: A memory-based text processing view. Journal of Experimental Psychology: Learning, Memory, \& Cognition, 24, 1200-1210.

O'Brien, E. J., Shank, D. M., Myers, J. L., \& Rayner, K. (1988). Elaborative inferences during reading: Do they occur on-line? Journal of Experimental Psychology: Learning, Memory, \& Cognition, 14, 410-420.

PotTs, G. R., Keenan, J. M., \& Golding, J. M. (1988). Assessing the occurrence of elaborative inferences: Lexical decision versus naming. Journal of Memory \& Language, 27, 399-415.

Rapp, D. N., Gerrig, R. J., \& Prentice, D. A. (2001). Readers' traitbased models of characters in narrative comprehension. Journal of Memory \& Language, 45, 737-750.

RiZZELla, M. L., \& O'BRIEN, E. J. (1996). Accessing global causes during reading. Journal of Experimental Psychology: Learning, Memory, \& Cognition, 22, 1208-1218.
SANFORD, A. J. (1990). On the nature of text driven inference. In D. A. Balota, G. B. Flores d'Arcais, \& K. Rayner (Eds.), Comprehension processes in reading (pp. 515-535). Hillsdale, NJ: Erlbaum.

Schmalhofer, F., McDaniel, M. A., \& Keefe, D. (2002). A unified model for predictive and bridging inferences. Discourse Processes, 33, 105-132.

Seidenberg, M. S., Waters, G. S., SAnders, M., \& Langer, P. (1984). Pre- and postlexical loci of contextual effects on word recognition. Memory \& Cognition, 12, 315-328.

Singer, M., Graesser, A. C., \& Trabasso, T. (1994). Minimal or global inference during reading. Journal of Memory \& Language, $\mathbf{3 3}_{2}$ 421-441.

VAN DEN BRoEK, P. (1990a). The causal inference maker: Towards a process model of inference generation in text comprehension. In D. A. Balota, G. B. Flores d'Arcais, \& K. Rayner (Eds.), Comprehension processes in reading (pp. 423-445). Hillsdale, NJ: Erlbaum. VAN DEN BRoEK, P. (1990b). Causal inferences and the comprehension of narrative texts. In A. C. Graesser \& G. H. Bower (Eds.), Inferences and text comprehension (pp. 175-196). San Diego: Academic Press.

VAN DEN BRoEK, P. (1994). Comprehension and memory of narrative texts: Inferences and coherence. In M. A. Gernsbacher (Ed.), Handbook of psycholinguistics (pp. 539-588). San Diego: Academic Press.

VAN DiJK, T. A., \& KinTsch, W. (1983). Strategies of discourse comprehension. New York: Academic Press.

ZWAan, R. A., \& Radvansky, G. A. (1998). Situation models in language comprehension and memory. Psychological Bulletin, $\mathbf{1 2 3}$, $\underline{162-185 .}$

\section{NOTES}

1. Naming time is a widely used, and accepted, measure of inference activation, because it does not appear to be influenced by the contextchecking processes (i.e., Forster, 1981) that often make interpretation of lexical decision or recognition responses difficult (e.g., Potts, Keenan, \& Golding, 1988; Seidenberg, Waters, Sanders, \& Langer, 1984). See Keenan, Potts, et al. (1990; also Keenan, Golding, Potts, Jennings, \& Aman, 1990) for an excellent review of the methodological issues of examining inference activation.

2. Although differences in reading time measures can often be interpreted as the result of differences in the ease of backward integration, such interpretations are not a concern when using the contradiction paradigm developed by O'Brien and Albrecht (1992). In this paradigm, a target sentence is presented that fits well within the local context but conflicts with information located earlier in the discourse. A slowdown in reading time for the target sentence is taken as evidence that the earlier information must have been activated, and thus interfered with comprehension. Under these conditions, it is reasonable to interpret a slowdown in reading time as an indication that activation occurred. (See O'Brien \& Myers, 1999, and O'Brien, Cook, \& Peracchi, 2004, for reviews of the use of this methodology.)

(Manuscript received December 6, 2002; revision accepted for publication February 16, 2004.) 